\title{
Rediseño de las bases conceptuales de la marca Club Amigo
}

\section{Redesign of the conceptual bases of the Club Amigo brand}

Lic. Suleena Cespedes Pavot. ${ }^{1}$

\begin{abstract}
In today's globalized economy it is essential to differentiate your own products from those of your competition. For this, it is essential to have a brand that has distinctive capacity, and that provides value to the client and the hospitality industry is no stranger to this. In Cuba, the main objective of brand creation is to homogenize the quality and service standards in the hotels of the different chains, leaving aside the need to measure how distinctive the brand is in the market to guarantee a good positioning. For this reason, redesigning the conceptual bases of the Club Amigo brand of the Cubanacan Hotel Group to differentiate it in the market is the fundamental objective of this research. And for this purpose, the study was carried out in one of the hotels that comprise it, using different research methods and techniques that allowed determining the attributes and benefits that would favor the redesign, such as analysis and synthesis, induction/deduction, the historical-logical, the bibliographic and documentary review, as well as the survey, the Positioning Map, the evaluation matrix and hierarchy of attributes, and the Expert Criterion. In addition, statistical-mathematical techniques such as sampling, Cronbach's Alpha, frequency analysis, the coefficient of expertise, and the Kendall coefficient were used. The results obtained made it possible to redesign the conceptualization of the Club Amigo brand in such a way that it can be identified by customers who choose it and that it differs from other brands.
\end{abstract}

Key Words: Brand Club Amigo, Differentiation, Brand Value, Positioning

\section{Resumen}

En la economía globalizada actual resulta fundamental diferenciar los productos propios de los de la competencia. Para ello es esencial contar con una marca que posea capacidad distintiva, y que le brinde valor al cliente y la industria de la hotelería no es ajena a esto. En Cuba, el objetivo principal de la creación de marcas es homogenizar los estándares de calidad y servicios en los hoteles de las diferentes cadenas, dejando de lado la necesidad

\footnotetext{
${ }^{1}$ Licenciada en Turismo, Facultad de Turismo, Universidad de La Habana sul3cespedes@gmail.com
} 
de medir cuán distintiva es la marca en el mercado para garantizar un buen posicionamiento. Por ello, rediseñar las bases conceptuales de la marca Club Amigo del Grupo Hotelero Cubanacán para diferenciarla en el mercado, es el objetivo fundamental de esta investigación. Y con este fin, se realizó el estudio en uno de los hoteles que la integran, empleándose diferentes métodos y técnicas de investigación que permitieron determinar los atributos y beneficios que favorecerían al rediseño, tales como el análisis y síntesis, inducción/deducción, el histórico-lógico, la revisión bibliográfica y documental, así como, la encuesta, el Mapa de posicionamiento, la Matriz de evaluación y jerarquización de atributos, y el Criterio de expertos. Además, se utilizaron técnicas estadísticas-matemáticas como el muestreo, el Alpha de Cronbach, el análisis de frecuencias, el coeficiente de experticia, y el coeficiente de Kendall. Los resultados obtenidos, posibilitaron el rediseño de la conceptualización de la marca Club Amigo de manera tal, que pueda ser identificada por los clientes que opten por ella y que se diferencie de otras marcas.

Palabras Clave: Marca Club Amigo, Diferenciación, Valor De Marca, Posicionamiento

\section{Introducción}

El crecimiento de la industria hotelera, basado en el posicionamiento de sus marcas, ha sido muy utilizado por la mayoría de los grupos hoteleros internacionales, que han asumido una tendencia hacia una mayor segmentación de productos vacacionales con el fin de lograr una diferenciación a través de la tematización o especialización. El hecho de que el producto hotelero, que según Ayala (2008) está constituido por “...los servicios inmateriales y la elaboración y venta de productos vinculados al soporte físico hotel, para dar confort y hospitalidad, satisfacer ilusiones y facilitar la estancia a turistas y viajeros", necesita sobrevivir en un entorno tan intensamente competitivo, genera la necesidad de desarrollar una marca fuerte, como una de las formas de diferenciarse, dentro de este.

El nuevo mandato del marketing, por lo tanto, consiste en crear una marca poderosa, que como bien exponen Belío y Sainz (2007), no sea solo un nombre, un logo, ni tampoco el esfuerzo de comunicación que se haya podido realizar; sino que la marca inspire confianza y de ella emane una promesa relevante y diferenciadora, una marca capaz de crear valor para el consumidor, fenómeno definido por Aaker (1996) como "el conjunto de activos y pasivos vinculados a la marca, su nombre y símbolo, que incorporan o disminuyen el valor suministrado por un producto o servicio intercambiado a los clientes de la compañía"

Una de las problemáticas que se evidencian en la actividad hotelera cubana, es que muchas de las marcas existentes no se diferencian en el mercado, aun cuando se establecen en los manuales operativos de las mismas su concepto, viendo la acción de diferenciar como "resaltar las características del producto, ya sean sustanciales o accesorias, que pueden contribuir a que sea percibido como diferente de los demás y, en cierto modo, como relativamente único en el mercado".

El Grupo Hotelero Cubanacán S.A, constituido en 1987, es una de las compañías turísticas que goza de más prestigio en Cuba. Como parte del enfoque hacia la calidad 
con el que venía trabajando, se realizó la segmentación de sus hoteles en cinco marcas: Club Amigo, Brisas, Horizontes, Cubanacán y Hoteles E.

Las marcas Club Amigo y Brisas están destinadas a la modalidad de Sol y Playa, y entre ellas se evidencian similitudes que imposibilitan que se establezca una imagen clara de la marca en la mente de los consumidores, lo que repercute en la experiencia de marca para este. Ambas marcas están asociadas a atributos muy similares, e incluso algunos aspectos básicos de su conceptualización es reiterativa. El elemento que más lo diferencia es la categorización de los hoteles, y por consiguiente los estándares físicos inherente a cada tipo de categorización y el precio; porque en la práctica los estándares de servicio son idénticos, sin una clara diferenciación por parte de los clientes que han visitado hoteles de las dos marcas. Sin embargo la marca Brisas se encuentra mejor posicionada en el mercado que la marca Club Amigo, acorde a los informes de satisfacción del cliente y otros estudios realizados por la cadena. Siendo esta última la que peor rendimiento presenta, pues no cuenta con elementos suficientes para asegurarse un lugar en el mercado.

La situación antes descrita condujo a plantearse el siguiente problema de investigación: ¿Cómo posicionar de manera diferenciada la marca Club Amigo en el mercado?

Como alternativa de solución a esta problemática se plantea la siguiente hipótesis:

Un rediseño en la conceptualización de la marca Club Amigo sobre la base del valor que entrega al cliente permite su diferenciación en el mercado.

El objetivo general que se persigue con esta investigación: Rediseñar las bases conceptuales de la marca Club Amigo, del Grupo Hotelero Cubanacán, para diferenciarla en el mercado.

\section{Objetivos específicos:}

1. Establecer las bases conceptuales, metodológicas y los antecedentes de la investigación.

2. Caracterizar la marca Club Amigo desde la perspectiva del valor que entregan al mercado.

3. Identificar los atributos que asocia el cliente, de manera más significativa, sobre la marca Club Amigo.

4. Determinar los elementos esenciales que condicionan las bases conceptuales de la marca Club Amigo.

Dentro de los métodos teóricos, se utilizó el análisis y síntesis e inducción/deducción, los cuales permitieron profundizar en el conocimiento de las principales características y regularidades de la actividad, sobre la base de juicios, enfoques y criterios. Se emplearon, además la revisión bibliográfica y documental, las que apoyaron la búsqueda de la información pertinente.

Dentro de los métodos empíricos, fueron utilizados, la encuesta, el Mapa de posicionamiento, la Matriz de evaluación y jerarquización de atributos, y el Criterio de Expertos, aplicando los respectivos instrumentos para cada uno de ellos. Se utilizaron 
técnicas estadísticas matemáticas asociadas a dichos métodos empíricos como el muestreo, el análisis de frecuencias, el Coeficiente Alpha de Cronbach, el coeficiente de experticia, y el Coeficiente de Kendall.

\section{Trayectoria metodológica de la investigación.}

La trayectoria metodológica (Figura 1) seguida por la autora, está compuesta de 4 fases que responden a los objetivos generales y específicos de la investigación.

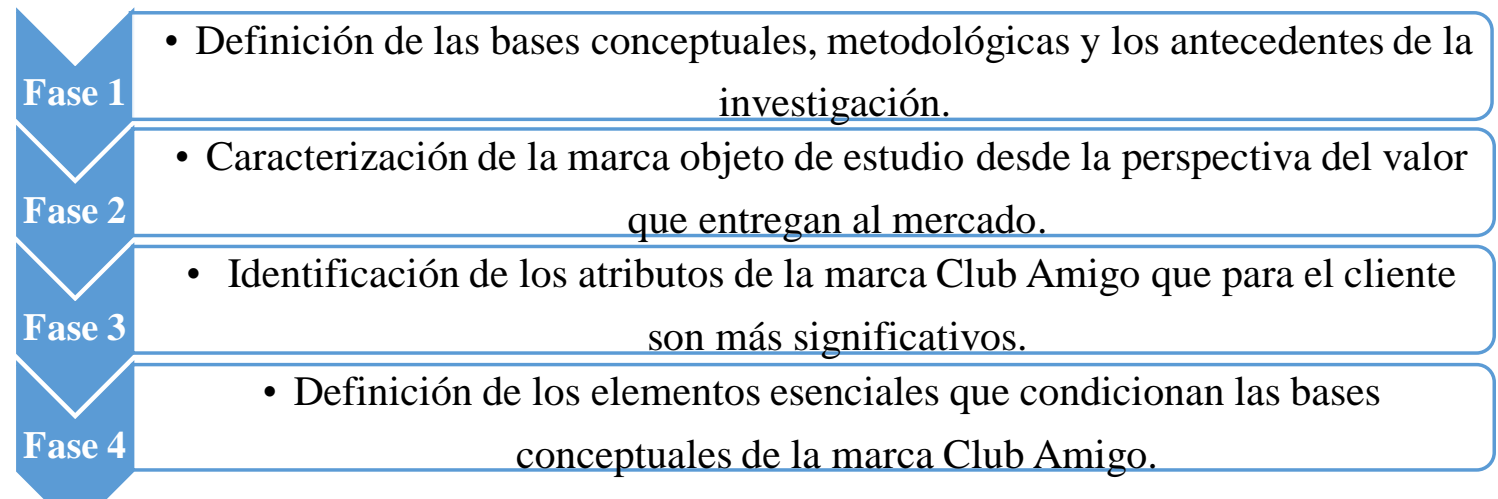

Figura 1. Trayectoria metodológica de la investigación.

Fuente: Elaboración Propia

En la primera fase se establecieron los fundamentos teóricos de la investigación en torno al tema estudiado con el objetivo de conocer el estado del arte sobre la temática a investigar, así como, determinar los aspectos esenciales que sirven de base a la investigación. Para ello se empleó la revisión bibliográfica y documental para obtener información basta que proporcionara un contexto y una justificación a la investigación que se llevó a cabo. Además, se usó el análisis-síntesis de toda la información encontrada, lo cual junto a la inducción- deducción de esta información permitió determinar el marco teórico.

La segunda fase tiene como fin realizar un análisis exhaustivo acerca de las fortalezas y debilidades que posee la marca Club Amigo, en cuanto al valor que entregan al mercado, utilizándose para ello el Modelo del Valor Capital de la Marca basado en el Cliente (Modelo VCMBC), propuesto por Keller (2008).

La premisa básica del Modelo VCMBC es que el poder de una marca depende de lo que los clientes han aprendido, sentidos y escuchado o visto de ella como resultado de sus experiencias con el paso del tiempo. En otras palabras, el valor de una marca depende de lo que reside en la mente del consumidor. Es por ello que se utiliza este modelo, aunque solo se hace como instrumento de diagnóstico del valor que brinda la marca Club Amigo al mercado, sin llegar a determinar el efecto deferencial que el conocimiento de la marca genera en la respuesta del cliente hacia el marketing.

En aras de evaluar la conciencia que se tiene de la marca Club Amigo, la formación de asociaciones fuertes, favorables y únicas y sentimientos positivos hacia ella, y la lealtad 
creada hacia la misma, se escogieron determinados criterios de evaluación por cada una de las etapas que ilustra el Modelo VCMBC. A estos, la autora decidió incorporarle el criterio "Posicionamiento", puesto que el objeto de estudio de la presente investigación devino de la necesidad de posicionar de manera diferenciada la marca Club Amigo. Entonces, se hace necesario conocer cómo perciben los consumidores los productos de esta marca, de acuerdo a una serie de preferencias que estos tengan y en relación a otros productos o marcas competitivas, pues la posición del producto y su diferenciación no tendría sentido en la mente del cliente si no existieran puntos de comparación con otros productos.

Para el desarrollo de esta fase, se aplicaron diferentes técnicas e instrumentos, a partir de la utilización de los métodos teórico, empíricos y estadístico- matemáticos, tales como: la encuesta, el Mapa de posicionamiento, la revisión bibliográfica, el Coeficiente alfa de Cronbach para validar la confiabilidad de la encuesta y el análisis de frecuencia y técnica de muestreo, apoyadas por las herramientas estadístico-matemáticas que correspondían en cada caso.

La encuesta tuvo como objetivo identificar las fortalezas y debilidades que presenta la marca Club Amigo, con respecto el valor que entrega al mercado, y fue elaborada en función de los criterios de evaluación seleccionados del Modelo VCMBC.

Se escogió el Hotel Club Amigo Ancón para aplicar las encuestas, por ser el único hotel marca propia de la marca Club Amigo entre todos los existente en los destinos Varadero y Trinidad; pues no tendría sentido evaluar el resto de los hoteles que operan bajo los estándares de la cadena hotelera extranjera que los gestiona, cuando lo que se busca es evaluar el valor que brinda la Marca Club Amigo por sí sola.

El resto de los hoteles Club Amigo marca propia no fueron objeto de estudio en esta investigación, atendiendo a que los territorios donde están ubicados (Cienfuegos, Camagüey, Santiago de Cuba, Holguín, y Granma), por su lejanía, eran de difícil acceso para la autora.

La cantidad de clientes que cumplieron con los criterios establecidos para la determinación de la población durante la etapa de recogida de información fue de 891 clientes, pudiéndose determinar, mediante un muestreo probabilístico, un tamaño de muestra de 269 clientes.

Para estimar la confiabilidad de las encuestas aplicadas se determinó el coeficiente Alfa de Cronbach. El valor obtenido fue de 0.870 , y se considera una fiabilidad aceptable. Esto corrobora que el cuestionario aplicado tiene coherencia en su estructura y escala de medición.

Se utilizó el Mapa de posicionamiento como herramienta que permitió conocer en qué lugar se encuentra la marca Club Amigo, respecto a su competencia, en la mente del consumidor, gráficamente y en relación a varios atributos. 
Para la determinación del marco competitivo se tomó como referencia el Hotel Club Amigo Ancón, hotel con el que se venía trabajando desde la fase anterior. Para ello, se tomaron en cuenta varios criterios de selección:

- Hoteles de sol y playa marca propia en los destinos Varadero y Trinidad.

- Hoteles con igual categoría que el Hotel Club Amigo Ancón.

- Hoteles enfocados al mismo segmento de mercado que el Hotel Club Amigo Ancón.

- Hoteles con igual propuesta de valor que el Hotel Club Amigo Ancón.

Identificándose finalmente, el Hotel Acuazul de la marca "Solarena" de la cadena Islazul, el Hotel Sun Beach de la marca "Estaciones" de la cadena hotelera Gran Caribe, el Hotel Villa Tortuga de la marca "Hola Club" de la misma cadena, y finalmente el Hotel Brisas del Caribe de la marca "Brisas", perteneciente al propio Grupo Hotelero Cubanacán, como principal competencia del Hotel Club Amigo Ancón.

Para identificar los atributos determinantes que influencian la percepción y decisión de compra de los clientes, a través de una investigación cualitativa, se recurrió a la revisión bibliográfica, esta tuvo como objetivo listar los atributos que podrían caracterizar al segmento de mercado familias (principal segmento de mercado de la marca objeto de estudio y de su competencia).

Se consultó documentación referida fundamentalmente a segmentación de clientes y determinación de atributos buscados por cada segmento. Luego, se realizó un análisis síntesis e inducción - deducción de la información. Finalmente, fue posible establecer un listado (Tabla 1) de aquellos atributos que pudieran ser apreciados por el principal segmento de mercado de estas marcas.

Tabla 1. Atributos más apreciados por el segmento de mercado familias.

\begin{tabular}{cc}
\hline Segmento & $\begin{array}{c}\text { Atributos apreciados como } \\
\text { muy importantes }\end{array}$ \\
\hline \multirow{2}{*}{ Familia } & Seguridad \\
Confort \\
& Limpieza \\
& Ubicación \\
& Variedad de servicios \\
& Personalización del servicio \\
\hline
\end{tabular}

Fuente: Elaboración propia partiendo de la revisión bibliográfica.

Para reunir los datos sobre las percepciones de los clientes sobre las marcas del conjunto competitivo más cercano a la marca Club Amigo, se utilizó la encuesta. Para su aplicación fue necesario el empleo de la técnica estadística de muestreo, utilizando el mismo procedimiento que el anteriormente usado en el cálculo de la muestra de clientes del Hotel Club Amigo Ancón. Resultando los tamaños de muestras de cada entidad que se exponen en la siguiente tabla:

Tabla 2. Muestra de turistas encuestados por hotel. 


\begin{tabular}{ccccc}
\hline Hoteles & $\begin{array}{c}\text { Hotel } \\
\text { Brisas del } \\
\text { Caribe }\end{array}$ & $\begin{array}{c}\text { Hotel } \\
\text { Acuazul }\end{array}$ & $\begin{array}{c}\text { Hotel Sun } \\
\text { Beach }\end{array}$ & $\begin{array}{c}\text { Hotel } \\
\text { Villa } \\
\text { Tortuga }\end{array}$ \\
\hline Muestra & 152 & 68 & 77 & 93 \\
\hline
\end{tabular}

Fuente: Elaboración propia.

Con el fin de apreciar el posicionamiento que tiene el Hotel Club Amigo Ancón con respecto a los restantes hoteles, se diseñaron dos mapas representados por gráficos de burbuja en 3D, teniendo en cuenta tres atributos diferentes para cada mapa, en uno se representan los atributos seguridad, limpieza y ubicación, y en el otro los atributos variedad de servicios, personalización del servicio y confort.

La tercera fase de la presente investigación tuvo como objetivo determinar los principales atributos que evoca la marca en el mercado, para así formular un nuevo concepto para la misma. Para llevar a cabo la fase se emplearon técnicas como la revisión bibliográfica, técnicas estadísticas, la encuesta y la Matriz de evaluación y jerarquización de atributos.

Le encuesta es la misma que se les aplicó a los 269 clientes en la primera fase de la investigación, sin embargo, la pregunta 4 es la que tributa a esta tercera fase, pues hace que el cliente defina los atributos que están presentes en el hotel donde se hospeda, que los evalúe y especifique el nivel de importancia que le concede a cada uno, asignándoles valores como opciones de respuesta.

Por otra parte, la Matriz de evaluación y jerarquización de atributos permitió identificar cuáles eran aquellos atributos que el segmento de mercado al que está dirigida la marca valoraba más, que suponen un beneficio para ellos, y que por lo tanto deben estar presentes en la marca objeto de estudio.

La cuarta y última fase de la trayectoria metodológica, tiene como objetivo definir los elementos que conforman la propuesta de la nueva conceptualización de la marca Club Amigo. Para llegar a la misma, la autora se apoyó en el análisis y la síntesis y la inducción - deducción, fundamentalmente.

Con el fin de validar la propuesta final de esta investigación se utilizó el criterio de expertos. Una vez seleccionados los expertos, se procedió a aplicarles un cuestionario para validar la propuesta de la nueva conceptualización de la marca Club Amigo. Por último y para determinar el nivel de concordancia entre las opiniones de los expertos, se utilizó el Coeficiente de Kendall (W).

\section{Resultados}

Resultados de las fases de la investigación. Análisis.

Caracterización de la marca objeto de estudio desde la perspectiva del valor que entregan al mercado.

Las informaciones obtenidas en las encuestas aplicadas en el Hotel Club Amigo Ancón, en referencia a los datos generales del encuestado, permiten afirmar que la principal 
motivación de viaje de los clientes que se hospedan en esta entidad es vacaciones; sin embargo, también es considerable la cantidad de clientes que tienen como motivo de viaje el conocimiento de otra cultura, motivación que se ve justificada precisamente por la ciudad en la que se encuentra enclavado el hotel objeto de estudio: Trinidad, villa que cuenta con uno de los complejos arquitectónicos más hermosos y mejor conservados de América y que fue declarada por la Unesco como Patrimonio de la Humanidad.

Aproximadamente el $64 \%$ de los clientes pertenecen al género femenino, en las edades comprendidas de 26 a 40 años, aunque se observó la presencia clientes de todos los grupos etarios, en especial niños, aunque estos no fueron considerados como parte de la población a encuestar. El 59\% alegó hospedarse en el hotel en compañía de la familia, mientras que el $15 \%$ lo hizo en compañía de familiares y amigos, siendo entonces el segmento de familias el público objetivo del hotel, y por consiguiente de la marca. Entre los principales mercados que atiende se encuentran Canadá y el mercado nacional, que ha ido en aumento en los últimos años, aunque se destacan otros como Francia, Alemania, Chile y España, en ese orden.

A continuación, se exponen los resultados obtenidos en la encuesta aplicada a los clientes alojados en el Hotel Club Amigo Ancón, que responde a los criterios del Modelo VCMBC seleccionados para diagnosticar el valor que entrega la marca Club Amigo al mercado.

- Prominencia de la marca

Con el fin de medir la conciencia que los clientes tenían de la marca Club Amigo se les preguntó si la conocían y si ya se habían hospedado en otras ocasiones en algún hotel de esa marca. La figura 2 y 3 exponen los resultados obtenidos:

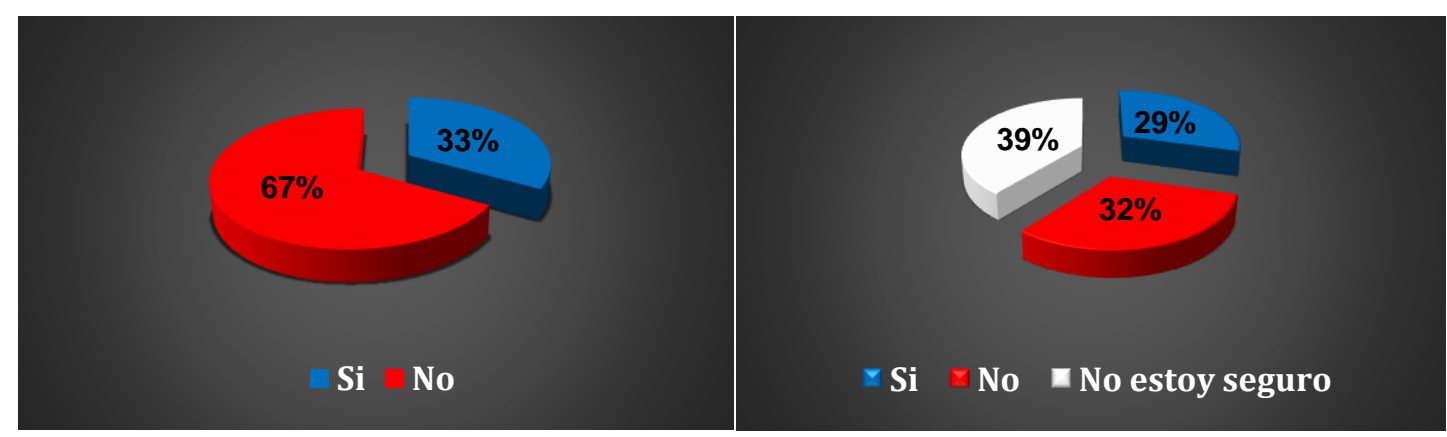

Figura 2. Nivel de Conocimiento de la marca Club Amigo.

Fuente: Elaboración propia

Figura 3. Exposición previa del cliente a la marca Club Amigo.

Fuente: Elaboración propia

Los resultados demuestran que los clientes, en su mayoría, desconocen de la existencia de la marca Club Amigo, pues el 67\% de los encuestados alegó no conocerla. Es decir, la marca no cuenta con reconocimiento ni recordación de producto, por lo que el cliente no se siente identificado o familiarizado con ella.

Incluso, llama la atención que el 39,03\% de los clientes (para un total de 105) fue incapaz de confirmar su exposición previa a la marca, es decir, reconocerla como la marca de un hotel en el que se hubieran alojado anteriormente. Esto hace que la marca Club Amigo 
no sea notoria para los consumidores, que no son capaces de asociar información a ella, condición esta que es necesaria para la creación del valor de marca, pues influye en la formación y fortaleza de las asociaciones que constituyen la imagen de marca.

Se hace necesario, entonces, crear una conciencia de la marca Club Amigo aumentando la familiaridad con ella a través de una exposición repetida (para su reconocimiento) y creando asociaciones fuertes con el producto $\mathrm{u}$ otras pistas relevantes de compra $\mathrm{o}$ consumo (para el recuerdo de la marca).

- Desempeño de la marca

El desempeño alcanzado por la marca puede ser medido por la satisfacción del consumidor con la misma, pues no es más que la evaluación resultante de la experiencia de consumo, basada en la diferencia entre las expectativas previas y el desempeño real del pro $\neg$ ducto después de ser consumido. Los resultados obtenidos en cuanto a los niveles de satisfacción general de los clientes se muestran en la figura 4.

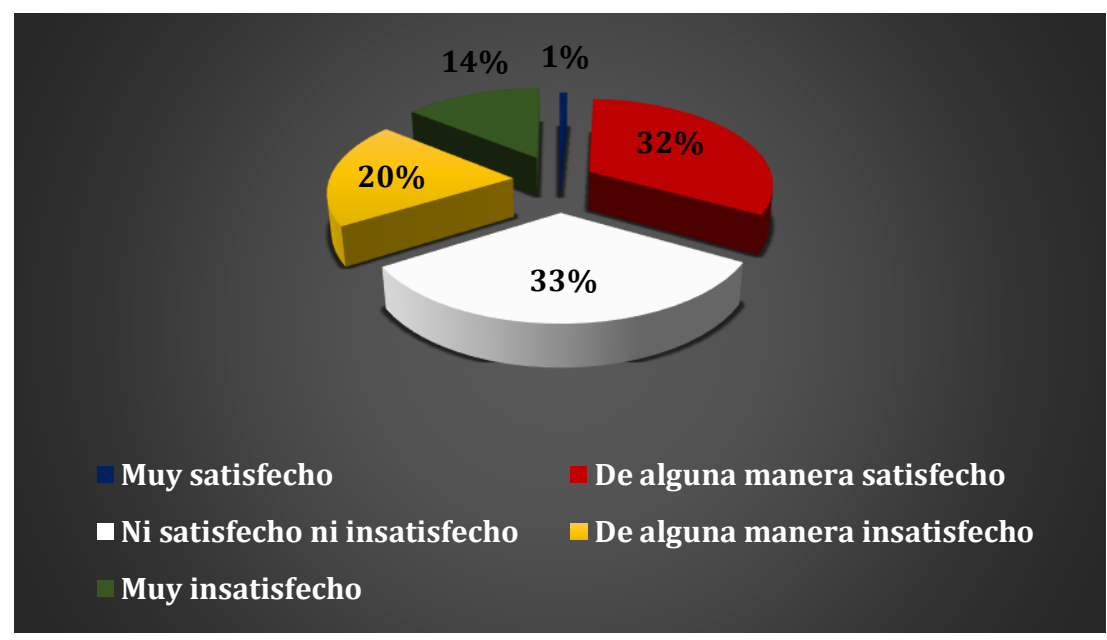

Figura 4. Nivel de satisfacción general de los clientes con la marca Club Amigo.

Fuente: Elaboración propia

Como se puede observar en la figura, solo el $1 \%$ de los encuestados se sintió muy satisfecho con el desempeño general del hotel. Mientras que el 32\% alegó sentirse de cierta manera satisfecho, esto significa que, de cierta forma, el cliente se siente conforme con el desempeño del hotel, sin embargo, considera que debe mejorar ciertos aspectos para poder satisfacer sus necesidades y cumplir con sus expectativas.

Resulta interesante el hecho de que el mayor por ciento radica en la categoría ni satisfecho ni insatisfecho, que son clientes cuya experiencia de consumo no fue del todo satisfactoria, sin embargo, tampoco al punto de que resultara desastrosa, ni que posea mayores valoraciones negativas que positivas sobre el producto luego de ser consumido. Este es un estado de opinión neutral que pudiera ser aprovechada a favor de la instalación y la marca para revertir la situación y mejorar el desempeño de la marca.

- Atributos y beneficios 
El análisis de los resultados sobre los atributos y los beneficios entregados por la marca Club Amigo, serán expuestos en la próxima sección.

- Calidad de la marca

La marca está también asociada con un determinado nivel de calidad que supone una garantía para el consumidor, generando así valor en diversas formas porque suministra la razón sobre la que se basa la compra; otorga la posibilidad de diferenciación y el consecuente posicionamiento de la marca en la mente del consumidor; da la opción de cargar un precio superior; puede ser significativa para los intermediarios del canal de distribución; y constituye la base para las estrategias de extensión de marca, a través del uso de su nombre para introducir nuevas categorías de producto.

Para la evaluación global de la calidad percibida por los clientes del Hotel Club Amigo Ancón, se tomaron parámetros o indicadores que responden a la escala SERVQUAL, propuesta por Parasuraman et al. (1985; 1988). En dicha escala se definen las 10 dimensiones principales de la calidad que los clientes deben tener en cuenta, que se clasifican en 5 categorías generales más importantes, que son: a) elementos tangibles; b) fiabilidad; c) capacidad de respuesta; d) empatía y e) seguridad, todas estas categorías fueron medidas a través de once indicadores. La Tabla 3 expone los resultados obtenidos.

Tabla 3. Calidad percibida por los clientes del Hotel Club Ancón en relación a los indicadores seleccionados.

\begin{tabular}{|c|c|c|c|}
\hline Indicadores & $\begin{array}{c}\text { Bueno } \\
(\%)\end{array}$ & $\begin{array}{c}\text { Regular } \\
(\%)\end{array}$ & $\begin{array}{c}\text { Malo } \\
(\%)\end{array}$ \\
\hline $\begin{array}{c}\text { Personal: conocimientos y } \\
\text { confianza }\end{array}$ & 85.87 & 14.12 & - \\
\hline Apariencia del personal & 89.59 & 10.4 & - \\
\hline $\begin{array}{c}\text { Buenos modales de } \\
\text { personal }\end{array}$ & 82.52 & 10.78 & 6.69 \\
\hline Trato especial & 66.17 & 24.16 & 9.66 \\
\hline Servicios puntuales & 22.67 & 59.47 & 17.84 \\
\hline Previsión de necesidades & 9.29 & 78.81 & 11.89 \\
\hline Comunicación activa & 89.59 & 10.4 & - \\
\hline Gestión de quejas & 21.93 & 76.95 & 1.11 \\
\hline $\begin{array}{c}\text { Equipamiento } \\
\text { (inmobiliario y equipos) }\end{array}$ & 19.7 & 53.15 & 27.13 \\
\hline Bebida y comida & 15.98 & 69.51 & 14.49 \\
\hline Actividades de animación & 36.05 & 50.92 & 13.01 \\
\hline
\end{tabular}

Fuente: Elaboración propia.

Como se observa en la tabla anterior, los indicadores que poseen mejor calidad son: apariencia del personal (con $89.59 \%$ de buenas evaluaciones), comunicación activa (con $89.59 \%$ ), personal: conocimiento y confianza (con $85.87 \%$ ), buenos modales del personal (con $82.52 \%$ ), y trato especial (con $66.17 \%$ de buenas evaluaciones). 
Esto evidencia que los indicadores relacionados con la dimensión de Recursos Humanos son los que mejor evaluación obtuvieron, la cual está asociada a la categoría de elementos tangibles, aunque el indicador comunicación activa también obtuvo buenas valoraciones

Por otro lado, los indicadores que recibieron mayores evaluaciones de malo y regular fueron: previsión de necesidades, gestión de quejas, bebida y comida, y equipamiento (inmobiliario y quipos). Este último, obtuvo mayores valoraciones de mala calidad $(27.13 \%)$ con respecto a los once indicadores evaluados. De forma global, la calidad percibida no es buena porque existen más indicadores valorados de calidad regular y mala que aquellos que para los clientes si presentan calidad. De igual manera, de las respuestas recibidas de la totalidad de los indicadores solo el $49.03 \%$ son valoraciones satisfactorias, mientras que el $50.95 \%$ de los resultados son de regular o malo $(41.7 \%$ y $9.25 \%$, respectivamente).

- Credibilidad de la marca

Este criterio se evaluó con el fin de conocer el grado en el cual los clientes consideran que la marca Club Amigo es creíble en término de tres dimensiones: habilidad percibida, fiabilidad y atractivo. El gráfico de la Figura 5 expone los resultados obtenidos.

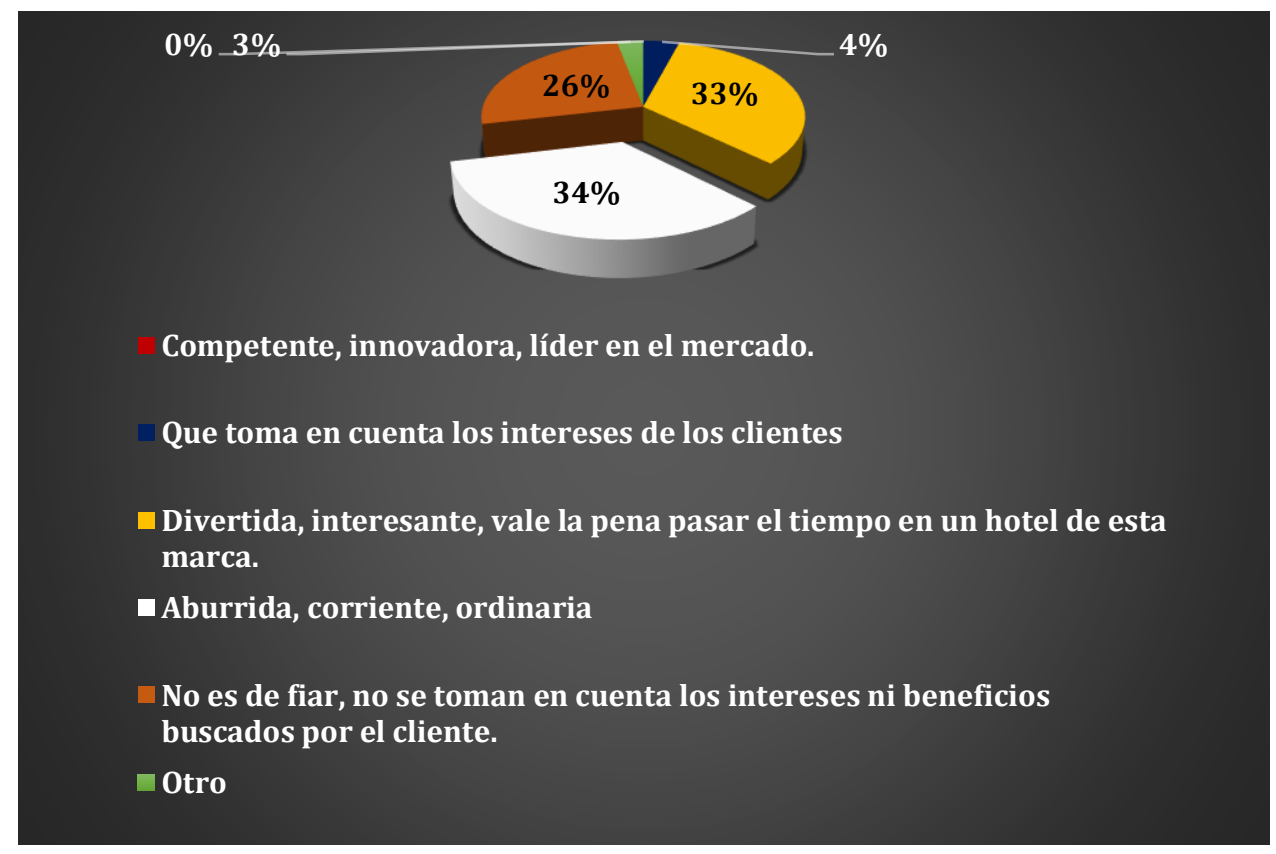

Figura 5. Nivel de credibilidad de la marca Club Amigo.

Fuente: Elaboración propia

El gráfico demuestra que el mayor por ciento de clientes (34\%) considera que la marca Club Amigo es aburrida, corriente, ordinaria, que es totalmente opuesto a lo que se supone que la marca debe evocar, según los manuales, y a la promoción que se le realiza a la marca, que realza estos atributos, en especial la diversión, como propios de todos los hoteles que integran la marca.

Por otro lado, el $33 \%$ de los clientes alegó que era divertida, interesante y que valía la pena pasar tiempo en un hotel de esta marca. Como se observa, existe cierta paridad entre 
las opiniones negativas y positivas que se brindan con respecto a la emoción provocada por la marca, aunque no llega a ser del todo significativa.

Sin embargo, se debe prestar atención a aquellos clientes que expresan que la marca no es de fiar, y que no toma en cuenta los intereses ni los beneficios buscados por el cliente $(26 \%)$. La falta de fiabilidad que ellos asumen viene determinada por las diferencias entre las expectativas que se crearon al observar o ponerse en contacto con la información promocional de hotel, y la realidad percibida una vez hospedados en el mismo, y que podrían catalogar de publicidad engañosa.

De forma general, tanto los clientes que catalogaron a la marca como aburrida, corriente y ordinaria y los que opinaron que no era una marca de fiar pues no prestaba atención a las necesidades de los clientes (representando el 60\% del total de clientes encuestados), le restan credibilidad a la marca Club Amigo a través de sus valoraciones. Esto constata que existe una gran brecha entre la impresión que recibe el cliente una vez consumido el producto, y lo que expone el Manual Operativo de la marca y la forma en que se vende el hotel a través de sus campañas de publicidad y promoción.

- Sentimientos hacia la marca

Los sentimientos hacia la marca son las respuestas y reacciones emocionales de los clientes hacia ella y se relacionan con el valor social que la marca evoca en el consumidor. Por ello se evaluó cuál de los tipos de emociones más importantes relacionadas con el desarrollo de una marca era evocado por la marca Club Amigo. La Figura 6 muestra los resultados:

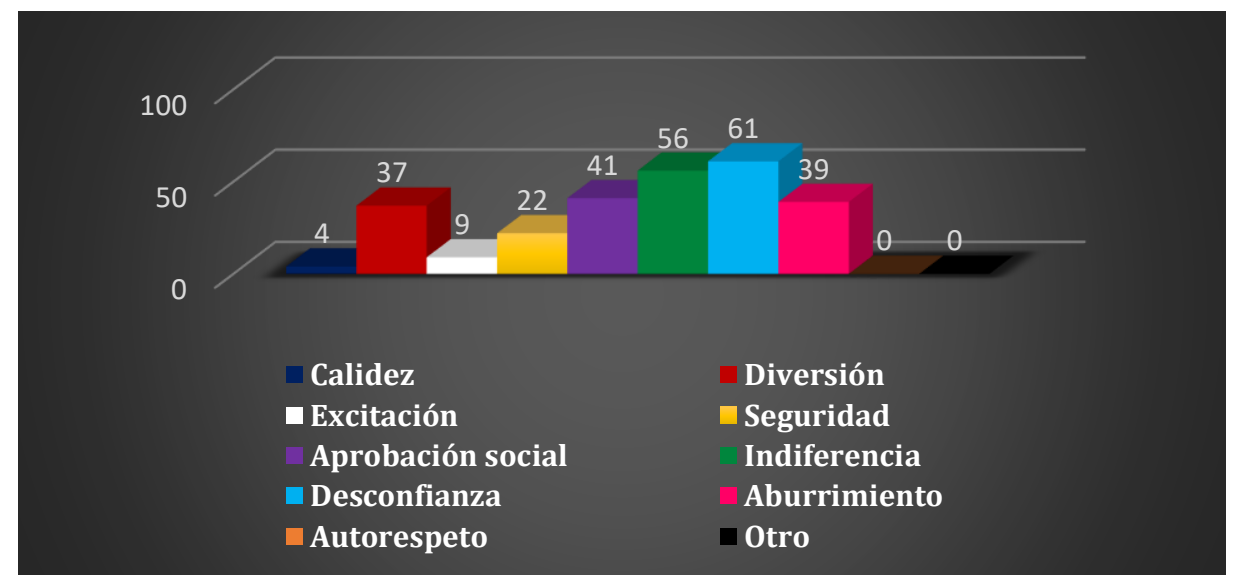

Figura 6. Sentimientos evocados por la marca Club Amigo.

Fuente: Elaboración propia

Los tres sentimientos que más transmite la marca son desconfianza, indiferencia, y aburrimiento, representando el 23\%, 21\% y 14\% del total de encuestados, respectivamente. Sin embargo, cada sentimiento por sí solo no representa un por ciento significativo, sino que se evidencia cierto equilibrio entre las evaluaciones, lo que significa que la marca aún no presenta un sentimiento específico asociado a ella, y por supuesto el sentimiento mayor ponderados son negativos, precisamente por los problemas de servicios y de calidad percibida, identificados con anterioridad. 
Cabe señalar dos cuestiones: la primera que el sentimiento calidez, que se supone que es un beneficio que debe aportar la marca a través de los atributos familiaridad y hospitalidad, que son la base de su actual conceptualización, es uno de los menos identificados por los clientes, con solo el $1 \%$ de los votos aproximadamente; y la segunda es que el sentimiento aprobación social, que fue identificado como un sentimiento inducido por la marca por el $15 \%$ de los encuestados, fue escogido en su mayoría por los clientes cubanos, que sienten que otros verán de manera favorable su apariencia y comportamiento si consumen este tipo de producto.

- Superioridad de la marca

Para tener un conocimiento del grado en que los clientes consideran que la marca Club Amigo es única y mejor que las demás, se propuso que los clientes establecieran una relación de superioridad o preferencia con respecto al resto de las marcas que posee la Cadena Hotelera Cubanacán, solo para medir su superioridad dentro de la cartera de marcas de la cadena, ya que posteriormente en el estudio de posicionamiento se evaluará su posición con respecto a otras marcas de sol y playa. La Figura 7 muestra los resultados.

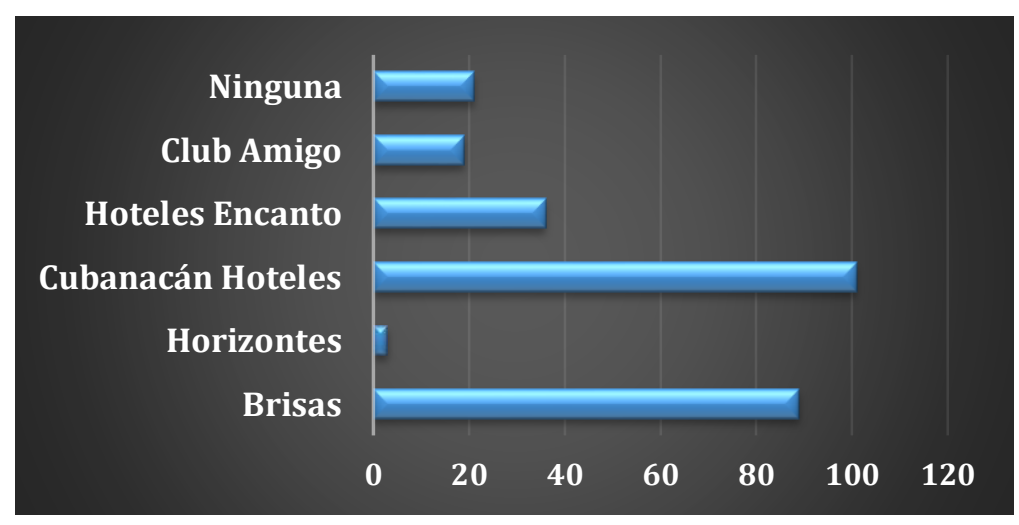

Figura 7. Nivel de preferencia de los clientes con respecto a las diferentes marcas de la Cadena Hotelera Cubanacán.

Fuente: Elaboración propia.

Se pudo constatar que la marca Cubanacán Hoteles, conformada por hoteles de ciudad, es la preferida entre las marcas de la Cadena Hotelera Cubanacán con el 38\% de los votos aproximadamente.

La marca Club Amigo, objeto de estudio de la presente investigación, se ubicó cuarta dentro de las cinco marcas evaluadas, con el 7\% de los votos, solo por encima de la marca Horizontes, especializada en turismo de naturaleza. Estableciendo una comparación entre las dos marcas de sol y playa de la cadena (Brisas y Club Amigo), la marca Brisas es de la preferencia de los consumidores 4,5 veces más que la marca Club Amigo, por lo que esta última no presenta ventajas distintivas o exclusivas que otra marca dentro de la misma cadena no pueda brindar.

- Posicionamiento 
Con el fin de apreciar el posicionamiento que tiene el Hotel Club Amigo Ancón con respecto a los restantes hoteles en cuestión, se diseñaron dos mapas representados por gráficos de burbuja en 3D. Cada uno de estos mapas permite apreciar una posición para cada hotel teniendo en cuenta tres atributos diferentes en cada mapa (Figuras 8 y 9).

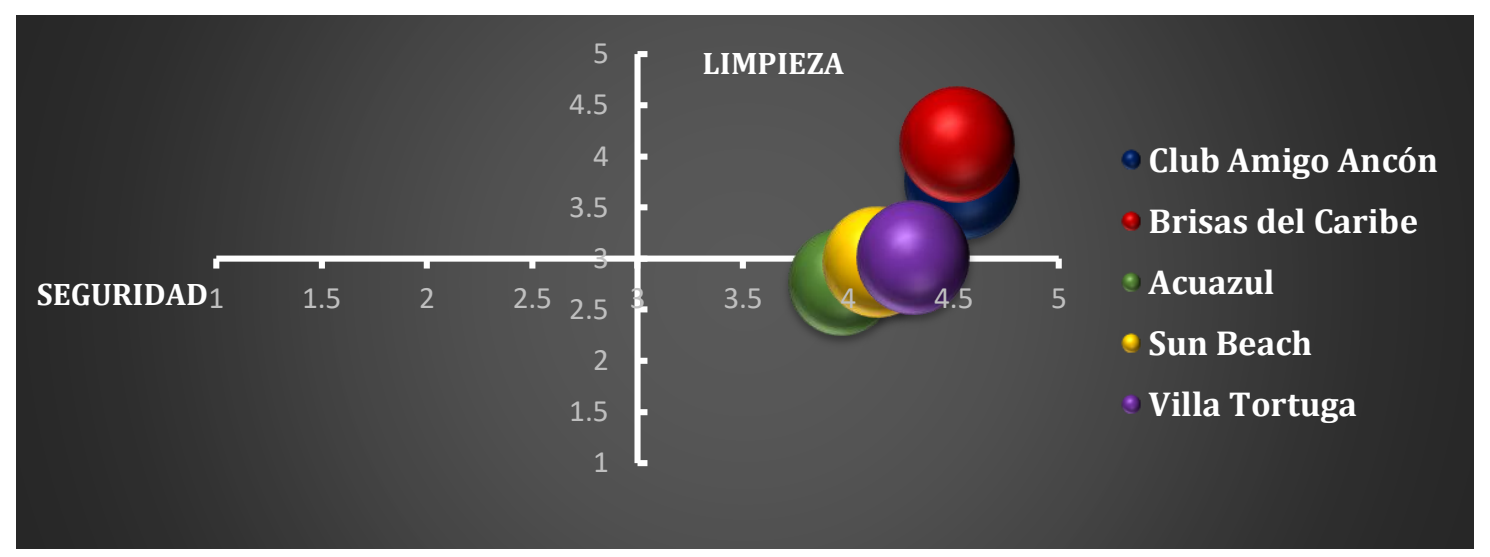

Figura 8. Mapa de posicionamiento respecto a los atributos seguridad, limpieza y ubicación.

Fuente: Elaboración propia.

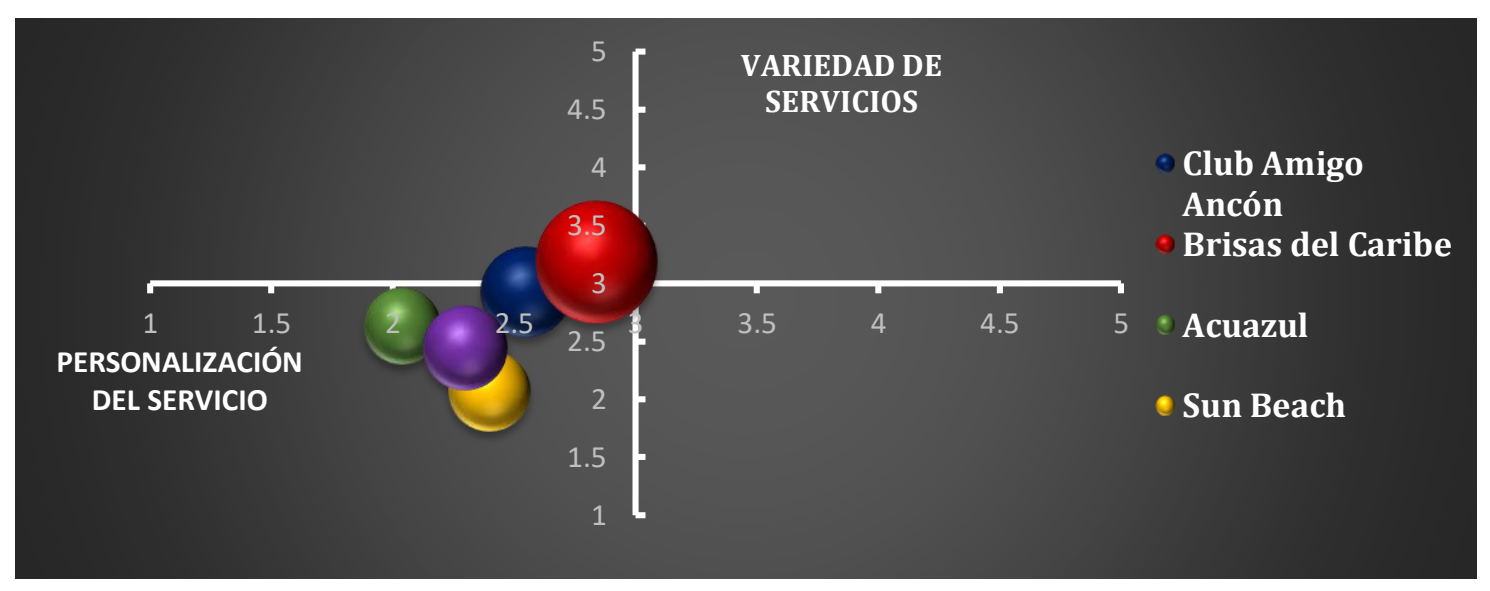

Figura 9. Mapa de posicionamiento respecto a los atributos variedad de servicios, personalización del servicio y confort.

Fuente: Elaboración Propia.

De los hoteles estudiados, el mejor posicionado es el Hotel Brisas del Caribe, a pesar de que no presenta una buena evaluación en todos los atributos estudiados. Dada la posición en que se encuentra el Hotel Club Amigo Ancón en el marco de referencia competitivo que aportan los mapas de posicionamiento realizados, se puede estimar que su competencia directa es el Hotel Brisas del Caribe, porque se encuentra ubicado visualmente más cercano a él, compartiendo más atributos en común, y puntos de paridad que las hacen más similares. Con respecto al resto de los hoteles, el Hotel Club Amigo Ancón se ubica en una posición superior en ambos mapas, evidenciando que posee un mejor desempeño de los atributos evaluados. 
Como parte del análisis, también se pudo evidenciar que existen atributos que apenas son cubiertos por algunas de las marcas, es decir son atributos en los que los hoteles evaluados obtuvieron un muy bajo desempeño, tal es el caso de los atributos variedad de servicios, personalización del servicio y confort. La Figura 10 muestra los promedios de evaluación por atributo.

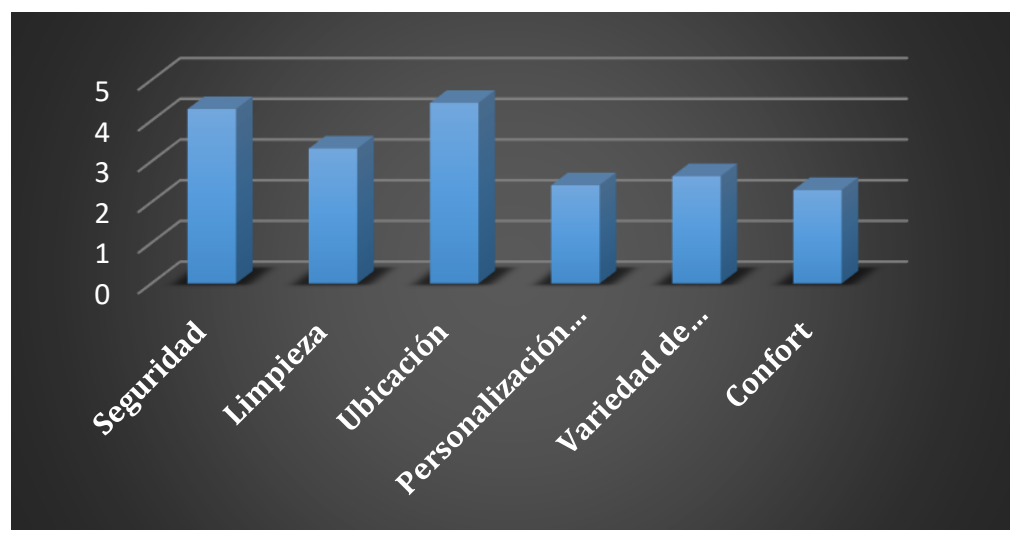

Figura 10. Promedio de evaluaciones de cada atributo.

Fuente: Elaboración propia

Estos atributos (variedad de servicios, personalización del servicio y confort) pueden ofrecer una oportunidad comercial, puesto que pueden ser aprovechados y de potenciarlos se podrían convertir en valores añadidos y diferenciadores de la marca, que se convertirían en una ventaja competitiva sostenible o "propuesta única de venta" que les dé a los consumidores una razón apremiante de por qué la deben comprar y le proporcione a dicha marca un mejor posicionamiento. Estos atributos podrían convertirse en puntos de diferencia que los consumidores asocien fuertemente con una marca, y que para ellos sea imposible encontrar en la misma magnitud en una marca competidora.

- Lealtad de la conducta

La marca es, fundamentalmente, una promesa. Por lo tanto, no basta con que satisfaga las necesidades y expectativas de los clientes, tiene que ser capaz, además, de despertar entusiasmo y crear lealtades duraderas. Para ello se han utilizado dos indicadores para medir la lealtad de la conducta que presentan los clientes hacia la marca Club Amigo: la intención de recomendación y la intención de repetir la visita. La Figura 11 muestra los resultados obtenidos:

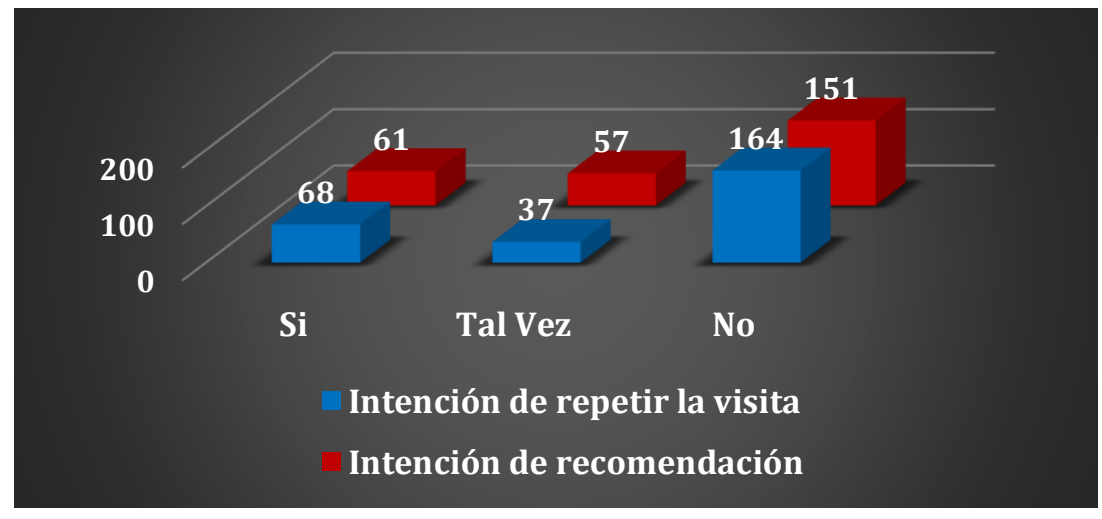


Figura 11. Medición de la lealtad del cliente hacia el hotel Club Amigo respecto a los indicadores intención de recomendación e intención de repetir la visita.

Fuente: Elaboración propia

La figura anterior demuestra que los clientes no presentan intención de repetir la visita al Hotel Club Amigo Ancón, ni recomendarían al hotel a otra persona, puesto que los dos indicadores recibieron mayores respuestas negativas ante la interrogante propuesta. Siendo el por ciento de compromiso de repitencia del hotel solo del $25 \%$ y el de recomendación del $23 \%$ aproximadamente, valores realmente ínfimos que evidencian la poca lealtad de la conducta de los clientes hacia la marca.

A pesar de que el objetivo de la evaluación de algunos los criterios propuestos en el Modelo VCMBC, era solo diagnosticar el valor que la marca Club Amigo entregaba al mercado, para luego identificar fortalezas y debilidades que pudieran ser utilizadas para el rediseño de la misma, si cabe destacar que cualitativamente, como la mayoría de los criterios evaluados no obtuvieron valoraciones satisfactorias, la marca no le brinda valor al segmento de mercado objetivo.

Una vez analizados los resultados obtenidos, y teniendo en cuenta los criterios aportados por Israel Calderón Fernández, actual Especialista de Calidad del Hotel Club Amigo Ancón, se pudieron identificar las siguientes debilidades y fortalezas.

\section{Debilidades:}

- No cuenta con reconocimiento ni recordación de producto.

- La marca no es superior al resto de las marcas que conforman la cartera marcaria de la Cadena Hotelera Cubanacán, en cuanto no presenta ventajas que otra no pueda ofrecer, ni siquiera con respecto a la otra marca destinada al turismo de sol y playa (Brisas).

- Deterioro de la planta habitacional por falta de reparación y problemas con el abastecimiento de agua que conllevan a que el atributo confort sea el peor evaluado por los clientes, y que los índices de calidad sean tan bajos.

- Evoca principalmente sentimiento de desconfianza en los clientes, dado la poca credibilidad que presenta la marca, pues la realidad que experimenta el cliente está muy lejos de coincidir con las expectativas que se crea.

\section{Fortalezas:}

- La mayoría de los atributos de relevancia para el cliente están presentes en la conceptualización actual de la marca.

- Es la segunda marca con mejor posicionamiento de las evaluadas.

- El Recurso Humano fue el indicador mejor evaluado en cuanto a la calidad percibida, elemento este que podría contribuir a la propuesta de valor de la marca, en especial cuando la idea base de ella parte de las relaciones amistosas entre el personal de contacto y el cliente. 


\section{Identificación de los atributos de la marca club amigo que para el cliente son más} significativos.

El análisis de la comparación entre los atributos del concepto que aparece en el Manual Operativo de la marca Club Amigo y la realidad demostrada a través de las encuestas, hizo evidente la falta de coherencia entre lo que está normado, el desempeño real de la marca que es percibido por el cliente y lo que realmente valora. Por ello se confeccionó un Matriz de evaluación y jerarquización de atributos, para precisar cuáles son los atributos que el segmento de mercado al que se encuentra enfocada la marca pondera con mayor fuerza y cuáles de estos presentan un mal desempeño, y por consiguiente evitan que la marca sea capaz de entregar valor al mercado.

La figura 12 muestra los resultados obtenidos en las encuestas aplicadas a los clientes hospedados en el Hotel Club Amigo Ancón, en cuanto a la valoración de la importancia y la evaluación del desempeño de los atributos seleccionados.

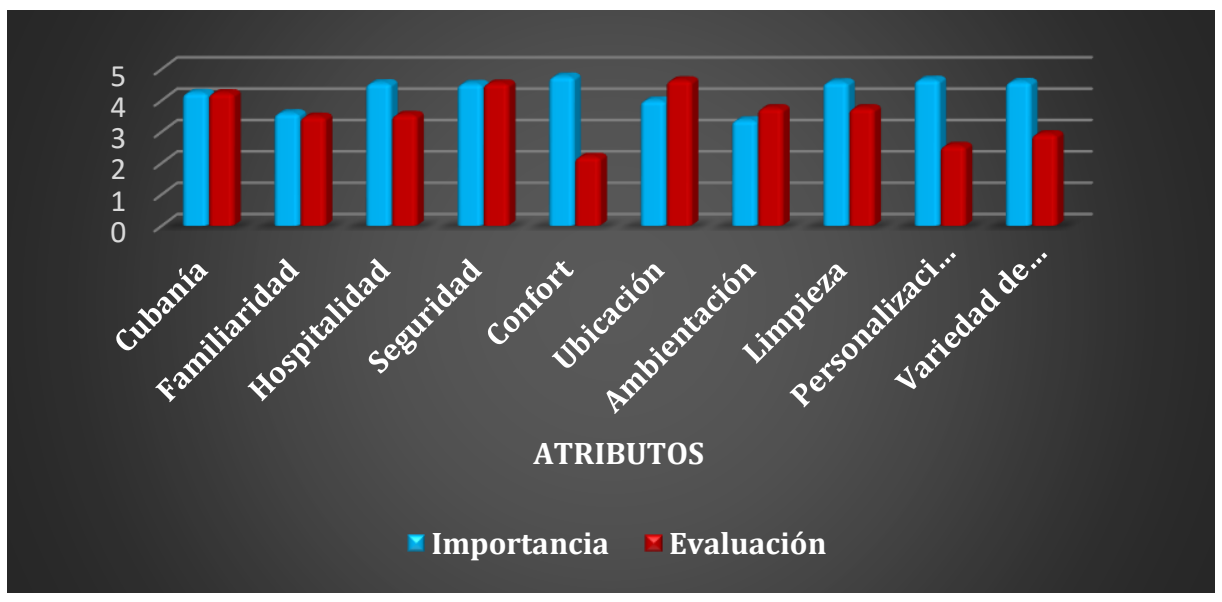

Figura 12. Resultados de la valoración de la importancia y la evaluación del desempeño de los atributos seleccionados.

Fuente: Elaboración propia

De la figura se puede deducir que los atributos de mayor prioridad para los clientes son los que presentan peor evaluación de su desempeño en el hotel, siendo estos conforts, personalización del servicio, variedad de servicios, limpieza y hospitalidad, en ese orden. Solamente los atributos seguridad y cubanía son los que presentan valores similares de importancia y evaluación (alta en ambos casos).

Una vez obtenidos los valores de la evaluación de los atributos y orden de importancia que presentaban para los clientes, se insertaron los resultados en la Matriz de evaluación y jerarquización de atributos (Figura 13). 


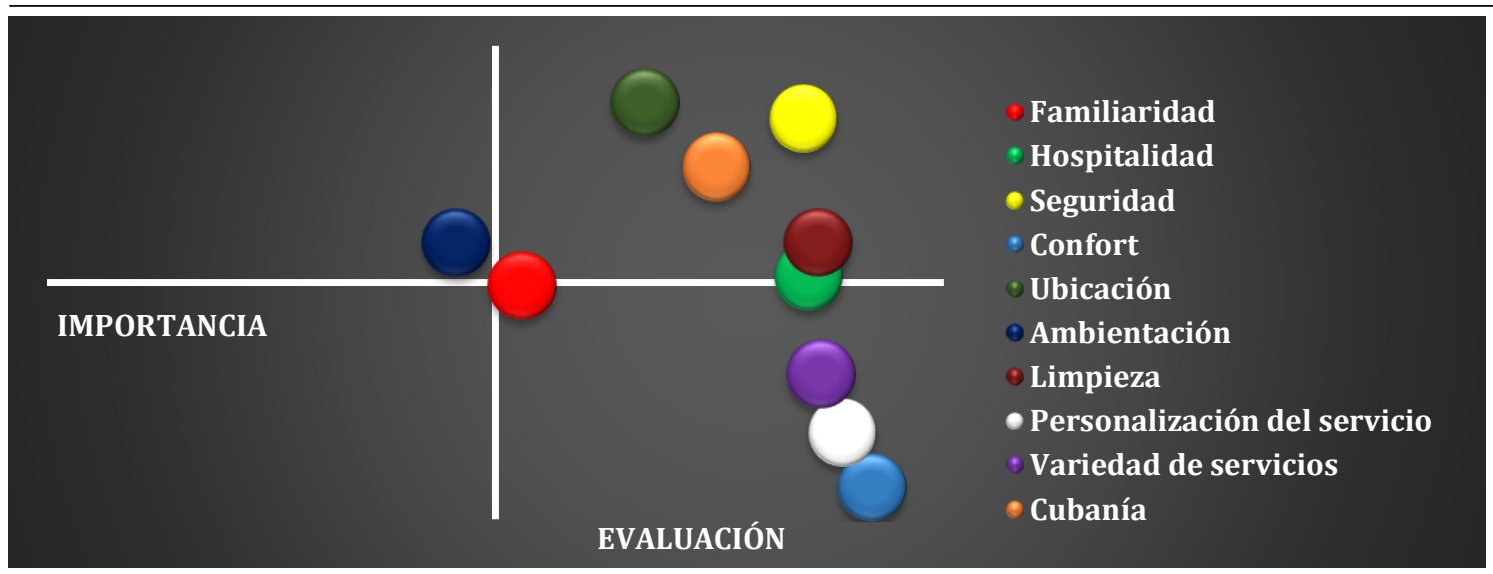

Figura 13. Matriz de evaluación y jerarquización de atributos.

Fuente: Elaboración propia.

En el cuadrante superior izquierdo se ubican aquellos atributos que no son de gran importancia para el cliente, sin embargo, estos reconocen que son entregados de manera correcta por el hotel, por lo tanto, su evaluación es alta. En este cuadrante solo se encuentra el atributo ambientación, que recibió un nivel promedio de importancia de 3.37. Es válido reconocer que dicho atributo es plasmado en la actual conceptualización de la marca como uno de los que debe evocar al cliente, y, sin embargo, resta de importancia para él.

En una situación similar se encuentra el atributo familiaridad, aunque este, por su ubicación en la matriz, no se encuentra posicionado por completo en ninguno de los cuadrantes, es decir que obtuvo valores medios en cuanto a la importancia que presenta para el cliente y la evaluación que el mismo le da a su desempeño en el Hotel Club Amigo Ancón. Este atributo es también es uno de los presentados en el concepto de la marca, e incluso es crucial para transmitir el valor o la idea de la cercanía y la amistad entre el consumidor y la marca, que expone el diseño actual de esta última; sin embargo, puede que carezca de importancia para el cliente porque no es transmitido de forma correcta y por lo tanto no provoca ninguna excitación o beneficio en él.

En el cuadrante superior derecho se encuentran aquellos atributos que son muy importantes para el consumidor y que son bien desempeñados por la instalación. Estos atributos deben formar parte del concepto de la marca, porque se busca ante todo brindarle al cliente el beneficio o el valor que este más aprecie en función de sus necesidades, y deben mantenerse desempeñados correctamente.

Los atributos sobre los que debe trabajarse son los que se encuentran ubicados en el cuadrante inferior derecho, porque son atributos que son de relevancia para el cliente, de hecho, en este caso son los tres más importantes (confort, personalización del servicio y variedad del servicio) y sin embargo no constituyen valor para el cliente porque no son entregados de forma correcta.

Definición de los elementos esenciales que condicionan las bases conceptuales de la marca club amigo. Propuesta. 
Una vez analizados los resultados obtenidos, ya se pueden establecer las premisas para definir las bases conceptuales de la marca Club Amigo y su materialización en la práctica. Estas premisas se exponen a continuación:

- El conocimiento previo de las necesidades básicas de los clientes, y las posibilidades reales que posee la organización es el sustento que condiciona la selección de los beneficios a entregar.

- Los beneficios tangibles a entregar deben disminuir las debilidades y potenciar las fortalezas que presenta la marca en cuanto al valor que entrega al mercado, para así crear lealtades duraderas.

- La diferenciación de la marca debe enfocarse en los atributos de relevancia para el cliente, que sean imposibles de encontrar en la misma magnitud en una marca competidora.

- La relación afectiva de amistad que subyace bajo la creación de la marca y por la cual recibe el nombre Club Amigo, debe estar siempre presente en la conceptualización de la misma.

Atendiendo a experiencias anteriores de conceptualizaciones de las marcas del grupo hotelero objeto de estudio, y de la propia conceptualización actual de la Marca Club Amigo, la nueva conceptualización de la marca Club Amigo, comprende seis componentes, que son:

\section{A. Orientación al mercado}

El segmento de mercado al que estará dirigida la marca es al segmento de familias (tanto nacional como extranjero) cuya motivación principal es vacacionar, y que consta de volumen, fidelidad y capacidad de recuperación frente a vaivenes económicos. Se podría decir que es un segmento maduro en demanda, pero emergente en oferta todavía, y cada vez buscan más la individualización o personalización del servicio, es decir, este mercado va a demandar un turismo familiar a la carta, adaptado incluso a cada uno de los integrantes de la familia.

\section{B. Concepto}

Ofrecer a nuestros clientes unas vacaciones familiares a la medida en las zonas litorales más hermosas del país, donde la variedad y personalización de los servicios en un ambiente de cubanía y familiaridad, crearán una experiencia inolvidable, condicionada por la hospitalidad, seguridad y confort de nuestras instalaciones.

\section{Atributos}

Los atributos que estarán asociados a la marca Club Amigo y que se deben manifestar en todos los hoteles que la componen son: personalización del servicio (este atributo va a constituir la base de la diferenciación significativa para la marca, especialmente en el contexto donde la mayoría de las marcas son similares respecto al resto de los atributos), variedad de servicios (determinada por la individualización del servicio para cada miembro de la familia), confort, limpieza, hospitalidad, seguridad, cubanía, ubicación y familiaridad. Para lograr la personalización del servicio se crearán diferentes clubes 
temáticos en las instalaciones de la marca, que diferirán en dependencia de las bondades que ofrezca la estructura de cada hotel que la conforma.

\section{D. slogan: ".. Ell mas leal de tus amigos..."}

Este es el slogan escogido para la marca Club Amigo porque el mismo cataloga a la marca como amigo del consumidor; utilizando incluso el pronombre posesivo "tu", que expresa primeramente informalidad, que no se traduce como falta de respeto sino como confianza, cercanía y entendimiento mutuo; y en segundo lugar demuestra pertenencia, pues la marca se crea por y para el cliente. Al denotarlo como "amigo" lo invita a la creación de una relación afectiva entre la marca y el consumidor, a lo cual están asociados valores como la lealtad, la incondicionalidad, la sinceridad y el compromiso; y es una relación que se cultiva con el trato asiduo y el interés recíproco a lo largo del tiempo.

Por otra parte, el slogan califica a la marca como la más "leal", representando la palabra lealtad el compromiso de defender algo o alguien en todo momento. Consiste en cumplir los compromisos realizados aun cuando las circunstancias sean distintas. Y es precisamente lo que pretende realizar la marca Club Amigo, ser leal a las necesidades y beneficios que busca el consumidor, independientemente de la rapidez con que cambien porque la lealtad no depende de las circunstancias, sino de la permanencia de los principios. De esa forma, el consumidor será capaz de devolver esa lealtad fidelizándose con la marca.

\section{E. Logotipo}

En la nueva conceptualización se propone realizarle modificaciones al logotipo actual de la marca Club Amigo, tales como:

- Incluir en los colores del logotipo los colores azul y blanco, además del color rojo ya existente en la actual versión. El color rojo se mantiene porque es adecuado para expresar la alegría entusiasta y comunicativa que debe evocar la marca, además es el más excitante de los colores, puede significar pasión, emoción, fuerza, vida y acción. Por otro lado, se propone el azul, que generalmente se asocia con la estabilidad y la seguridad, representando la lealtad, la confianza, el afecto, la fidelidad e incluso la amistad. Además, es el color utilizado para denotar todo lo relacionado con el mar. Finalmente se incorporaría el color blanco como matiz y balance entre los dos colores anteriormente descritos, denotando la armonía.

- Incluir una figura humana en el logotipo, que pudiera ser animada o incluso una imagen o forma que represente la figura humana sin tener que ser precisamente una. Esto le da vida a la idea de "Amigo" que se quiere lograr con la personalidad de la marca, la hace más humana, la acerca a personificar ese ideal que la identifica como tu amigo más leal.

- Mantener el símbolo del sol que posee actualmente, pero se propone modificar la figura que representa la playa porque da más sensación de una montaña, y lo que se quiere es que se identifique como una marca de sol y playa.

- Estándares. 
Luego de analizar los estándares plasmados en el Manual Operativo de la marca Club Amigo, y teniendo en cuenta los resultados de la investigación y las premisas propuestas, se realizaron ciertas modificaciones en los estándares actuales de la marca, algunas por adición y otras por sustitución, y se incluyeron nuevos. A continuación, se listan estas propuestas por cada una de las áreas claves del alojamiento turístico: el alojamiento, la alimentación y la animación.

Alojamiento:

- Estándares del servicio de recepción:

Dentro del proceso de check-in, el cliente tendrá la posibilidad de inscribirse en los clubes temáticos que ofrece la instalación, en correspondencia con las características particulares de cada una, cuyas especificaciones serán previamente explicadas por el personal de recepción. En el caso particular de los niños, los padres o tutores a su cargo serán los responsables de registrar al menor en el club que desee, dependiendo también de la edad que este tenga.

- $\quad$ Estándares físicos de las habitaciones:

Además de las habitaciones standard y tropical, se incluirá la habitación familiar, la cual dispondrá de más espacio y estará equipada para alojar bebés y niños.

\section{Alimentos y bebidas:}

- $\quad$ Estándares físicos de las áreas gastronómicas:

Incluir una dulcería-cremería dedicada a los niños. La decoración será alegre y llamativa, y el mobiliario estará acorde con el público al que estará dirigido el área (niños de 1 a 15 años). Aunque los adultos que deseen acompañar a los menores también lo podrán hacer.

[Sustitución] Se empleará la vajilla personalizada con la imagen corporativa con el logo de Cubanacán para los Restaurantes Buffet y otras áreas gastronómicas, incluidos (no así, para) los Restaurantes Especializados.

- Estándares de servicio en las áreas gastronómicas:

Las diferentes áreas de servicios gastronómicos servirán también de espacio para desarrollar las actividades de los diferentes clubes que se dispongan en la instalación, en especial los relacionados con la culinaria y la coctelería.

\section{Restaurante buffet}

- En el restaurante buffet se delimitarán zonas para adultos, para niños y zonas familiares, donde podrá acomodarse la familia completa.

- [Sustitución y Adición] Todas las mesas de los restaurantes tendrán sus tableros cubiertos con muletón o guata, así como emplear Doyles personalizados con el logo de la marca (mantel y cubremantel), en colores que armonicen con el diseño e imagen de la marca Club Amigo; y se emplearán mantel y cubremantel para determinadas ocasiones.

\section{Parrilladas o Ranchón de Playa:}

- [Sustitución] Sus horarios de servicio serán de 10:00 a.m. a 6:00 p.m. (11:00 a.m. a 5:00 p.m.).

\section{Snack-bares:}


- [Adición] La estructura de la oferta gastronómica consistirá básicamente en comidas rápidas (entrepanes, hamburguesas, perros calientes y snacks o picaderas), así como aguas, jugos, refrescos y cervezas dispensadas.

\section{Bares:}

- [Sustitución] Horario de servicio de los bares:

Lobby-bar Las 24 horas del día (de 9:00 a.m. a 11:00 p.m.)

Bar piscina De 10:00 a.m. a 6:00 p.m. (de 10:00 a.m. a 5:00 p.m.)

Bar playa De 10:00 a.m. a 6:00 p.m. (de 10:00 a.m. a 5:00 p.m.)

Café cantante, piano bar, sala de fiesta De 10:00 p.m. a 3:00 a.m. (de 11:00 p.m. a 2:00 a.m.)

\section{Animación y recreación:}

- Caracterización de la oferta de animación y recreación:

[Sustitución] Las actividades de las ofertas de animación y recreación se estructurarán en dependencia de los clubes que existan en cada instalación (se estructuran en tres sesiones principales: diurna, nocturna y para niños).

- $\quad$ Estándares para la oferta de animación y recreación:

[Sustitución y Adición] Teniendo en cuenta los posibles clubes temáticos que oferte cada hotel, las actividades de animación consistirán fundamentalmente en: Actividades festivas, Actividades formativas-creativas, Actividades Deportivas, Actividades náuticas, Actividades lúdicas, Actividades ecológicas y Actividades para niños (las expuestas en el Manual referentes al Club Infantil)

(Las actividades se reestructuraron teniendo en cuenta las dimensiones del ocio activo, adicionando algunas y suprimiendo otras)

Una vez que se describió la propuesta de la nueva conceptualización de la marca Club Amigo, la autora plantea un conjunto de acciones que se deben llevar a cabo para que el rediseño logre su objetivo, posicionar de manera diferenciada la marca Club Amigo en la mente del consumidor.

- Realizar las transformaciones necesarias en la estructura física de los hoteles y en los procedimientos que realizan para adaptarlos los más posibles a los estándares propuestos.

- Diseñar una estrategia de comunicación global que transmita el nuevo concepto de la marca y lo fije en la memoria de los consumidores para aumentar la familiaridad, y que integre los instrumentos tradicionales de publicidad, promoción, relaciones públicas, fuerza de ventas y marketing directo.

- Socializar la nueva conceptualización de la marca entre el personal de las instalaciones que pertenecen a la misma, para que sean capaces de identificar la nueva imagen del hotel a través de diversos estímulos que ayuden a su fácil reconocimiento.

- Formar equipos de revisión integrados por miembros de la Cadena Hotelera Cubanacán, que trimestralmente realicen comprobaciones sobre el estado de aplicación de los estándares del Manual en las diferentes instalaciones de la marca. 
Por otro lado, el hecho de que los clientes del hotel se encuentren en una actitud de indisposición a repetir su visita, requiere un esfuerzo para desarrollar acciones en pos de mejorar aquellos aspectos que puedan ser susceptibles de mejora por parte del establecimiento. A continuación, se exponen un conjunto de acciones que pudieran contribuir de cierta forma a mejorar la satisfacción del cliente o la calidad percibida por este, como condicionante del aumento de la competitividad del hotel objeto de estudio.

- Evaluar los procedimientos de limpieza y desinfección a partir del constante uso de las Listas de Chequeo.

- Garantizar la variedad de alimentos y bebidas, así como las condiciones de higiene alimentaria en los restaurantes, cafeterías, bares y chiringuitos.

- Implantación y mejora de sistemas de aprovechamiento del agua y la energía.

- Diseñar y aplicar un nuevo programa de animación en el hotel para diversificar la oferta de actividades de animación del mismo, otorgarle un valor diferencial y a la vez satisfacer las necesidades de los clientes.

- Cumplir con el programa de mantenimiento correctivo y preventivo de los equipos.

- Incrementar, en el plan de mantenimiento del hotel, más acciones preventivas relacionadas con el sector habitacional y las áreas nobles.

\section{Validación de la propuesta. Criterio de expertos.}

Luego de aplicarle el cuestionario a los expertos y tabular los resultados, se introdujeron en el programa estadístico "Statistic Program for Social Sciences” (SPSS) para Windows (versión 20.0).

El resultado del Coeficiente de concordancia de Kendall dio 0.642, lo que indica que el grado de asociación de las evaluaciones ordinales realizadas por los 10 expertos al evaluar la propuesta de rediseño de las bases conceptuales de la marca Club Amigo, fue alto, pues mientras más alto sea el valor, o mientras esté más cercano a 1 más fuerte será la asociación.

Cabe destacar que la mayoría de los aspectos evaluados en dicho cuestionario, recibieron muy buenas evaluaciones, es decir la mayoría de los expertos estuvo totalmente de acuerdo con las declaraciones que afirmaban que el rediseño realizado era original, exclusivo, que era capaz de producir lealtad en los consumidores, y lo más importante que la propuesta planteada permitía la diferenciación de la marca en el mercado.

\section{Conclusiones}

El desarrollo de esta investigación y los resultados obtenidos, permitieron arribar a las siguientes conclusiones:

- Las técnicas empleadas en la investigación, en particular el diagnóstico de la marca con respecto al valor que brinda al mercado, el estudio del posicionamiento de los productos de la competencia en la mente del consumidor con respecto a la marca estudiada, y la identificación de los atributos de mayor significación para 
el segmento de mercado objetivo, permitieron formular las premisas para el rediseño de las bases conceptuales de la marca Club Amigo.

- El valor de la marca basado en el cliente se refleja en la actitud que este adopta hacia la marca, establecida en las creencias relativas a atributos positivos del producto. La capacidad que tenga la marca de poseer atributos diferenciadores que la hagan única en el mercado, va a condicionar que sea positivo o no el valor que es capaz de entregar.

- Cualitativamente, la marca Club Amigo no le brinda valor al segmento de mercado objetivo puesto que la mayoría de los criterios evaluados del Modelo del Valor Capital de la Marca Basados en el Cliente (VCMBC) no obtuvieron valoraciones satisfactorias.

- Los atributos de la marca Club Amigo que resultan más importantes para los clientes son: personalización del servicio, variedad de servicios, confort, limpieza, hospitalidad, seguridad, cubanía, ubicación y familiaridad

- La propuesta refleja que el rediseño de las bases conceptuales de la marca Club Amigo, sobre la base del valor que entrega al cliente, permite su diferenciación en el mercado.

\section{Referencias bibliográficas}

Aaker, D. (1996). Measuring brand equity across products and markets. California Management Review, Vol. 38, 102-120.

Ayala, H. (2008). Apuntes sobre la comercialización hetelera. La Habana: Centro de Estudios Turísticos.

Belio, J., \& Sainz, A. (2007). Claves para gestionar precio, producto y marca: cómo afrontar una guerra de precio. Madrid: Especial Directos.

García, L. J. (2016). Medición del Valor de Marca mediante el modelo de Aaker: el caso de Paco \& Lola. Trabajo de fin de grado, Facultad de Economía y Empresas. Universidad da Coruña, La Coruña.

Grupo Hotelero Cubanacán SA. (2016). Manual Operativo de la Marca Brisas. La Habana.

Grupo Hotelero Cubanacán SA. (2016). Manual Operativo de la Marca Club Amigo. La Habana.

Keller, K. L. (2008). Strategic Brand Management: Building, Measuring, and Managing Brand Equity. Pesrson/Prentice Hall.

Kotler, P., \& Armstrong, G. (2008). Fundamentos del Marketing 8va ed. México: Pearson Educación. 
Rego, D. S. (2015). Determinación de competidores del hotel Santa Isabel. Trabajo de Diploma en Opción al Título de Licenciado en Turismo, Facultad de Turismo. Universidad de La Habana, La Habana.

Serra, A. (2003). Marketing Turístico. Madrid: ESIC.

Solorzano, P. V. (2018). Rediseño de la marca YÜNKE como posicionamiento de marketing de la empresa PANCER, en la ciudad de Bogotá. Trabajo de grado para optar al título de Administrador de Empresas, Facultad de Ciencias Administrativas y Contables. Universidad de La Salle, Bogotá. 


\section{PARA CITAR EL ARTÍCULO INDEXADO.}

Cespedes Pavot, S. (2021). Rediseño de las bases conceptuales de la marca Club Amigo. Explorador Digital, 5(1), 389-415. https://doi.org/10.33262/exploradordigital.v5i1.1509

\section{LCiencia}

El artículo que se publica es de exclusiva responsabilidad de los autores y no necesariamente reflejan el pensamiento de la Revista Explorador Digital.

El artículo queda en propiedad de la revista y, por tanto, su publicación parcial y/o total en otro medio tiene que ser autorizado por el director de la Revista Explorador Digital.
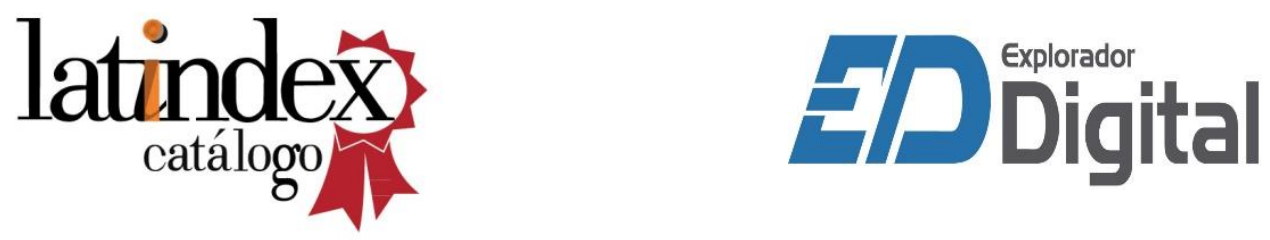